\title{
A vision for public health development
}

Public health has developed over time to encompass a range of issues including poverty, sanitation, working conditions, hygiene, health screening, immunisation, personal lifestyles and, more latterly, community and organisational development. Terms such as public health, social medicine, health promotion and more recently, health development, have been used to signpost changing thinking about public health. Health development, arguably is a term that encapsulates not only current thinking but also articulates a vision for service development for the future that is capable of mobilising a range of partners and agencies in a common cause of improving health. As someone who, as a local government officer, has been a public health practitioner for some time but who only recently has joined the formal public health fraternity as Chair of the Health Development Agency, such an inclusive term is particularly important.

There is growing international recognition that the development of health and wellbeing is one of the most important aspects of government policy and a key marker of a national success. It has been defined as "The process of continuous, progressive improvement of the health status of individuals and groups in a population", a definition that reflects the range of challenges we face at the start of the new century. ${ }^{1}$ But perhaps the overriding challenge is to ensure we do not forget the lessons of the past when developing new strategies and tactics.

Over 20 years ago the World Health Organisation (WHO) created "Health for All", a strategy with a definition of health that goes beyond the absence of disease, involving partnership and community participation-and that requires governments, organisations, communities and individuals to work together to improve health. ${ }^{2}$ Although we have learnt much about what does-and doesn't - work since publication of Health for All, there is still an ongoing need to capture evidence of good practice, which can inform future programmes. In order to promote good practice, practitioners, policy makers, and researchers need to cooperate to ensure that the evidence is translated into real and practical action, through the establishment of education and development programmes.

Current evidence shows that effective health development interventions share common characteristics: they are based on a proper assessment of need and are clearly focused $^{34}$; they are multifaceted; and are developed in conjunction with target communities. Successful interventions also tend to be sustained and delivered by well trained and supported workers. Success is further increased if interventions take place within a supportive strategic framework where there is effective cross agency collaboration.

The most crucial challenge, however, is to put health development at the heart of the policy development and implementation strategies of governments. Part of our vision for health development must be to unite and coordinate action across government, organisations and communities to tackle issues of equity, social inclusion and regeneration. We need to support and develop policy makers, practitioners, organisations and communities so that they can engage with the health development agenda. We must also really engage with communities so that they can make a full contribution to strategies as they develop; evidence suggests that unless health strategies have resonance with those on whom they are focused, the chances of achieving a sustainable impact are negligible. ${ }^{5}$

If the health development agenda poses a challenge for politicians it also poses challenges for epidemiology. ${ }^{6} \mathrm{Cer}-$ tainly, if we accept a definition of health that goes beyond the absence of disease there is a need to develop methodologies that can measure positive health and wellness as well as morbidity and mortality.

The UK government has begun to tackle the issues outlined above by developing a health strategy that recognises the social determinants of health and the need for a coordinated response across government and communities to bring about sustained health improvement. "Saving Lives" Our Healthier Nation, the white paper on public health that was published on 17 July 1999, sets out a series of bold challenges to all those who can contribute to sustained health improvement. ${ }^{7}$

It is part of a process of systematic reinvigoration of public health across the UK, which entails placing health development at the centre of the social policy agenda. The Health Development Agency has been established to help coordinate and develop this strategy. The new Agency will lead development of a comprehensive evidence base of what works in public health and health development, the establishment of standards and the uptake of best practice. It will also help coordinate health development activities across government, acting as an agent for organisational development. As the first national health agency of its kind in the world, it reflects the seriousness with which the UK government regards the health development challenge.

The current UK government's vision for health strategy is not radically different from that espoused over 20 years ago by WHO. What is different today is the growing international realisation in the UK and elsewhere that progress takes more than just declarations. Rather, what is needed is an approach that puts health development at the heart of policy development and implementation-one that puts "the public" back into public health. That is the challenge for the Health Development Agency.

YVE BUCKLAND

Health Development Agency, Trevelyan House, 30 Great Peter Street, London SW1P $2 H W, U K$

\footnotetext{
1 World Health Organisation. Health Promotion Glossary. HPR/HEP/98.1. Geneva: WHO, 1998

2 Primary Health Care Report of the International Conference on Primary Care. Alma-Ata, 6-12 September. Geneva: World Health Organisation, 1978.

3 International Union for Health Promotion and Education. The evidence of health promotion effectiveness. Shaping public health in a New Europe. A report for the European Commission. ECSC-EC-EAEC. Brussels: 2000.

4 Haglund B, Pettersson B, Finer D, et al, eds. Creating supportive environments for health. Public health in action. Geneva: WHO, 1996.

5 World Health Organisation. The fakarta declaration on leading health promotion into the twenty first century. HPR/HEP/41.97.4. WHO: Geneva, 1997. 6 Petersen A, Lupton D. The new public health. Sage, 1996.

7 Department of Health. Saving lives. Our healthier nation. London: Department of Health, 1999.
} 